\title{
Cerebellar and Ventricular Ependymal Tumor
}

National Cancer Institute

\section{Source}

National Cancer Institute. Cerebellar and Ventricular Ependymal Tumor. NCI Thesaurus.

Code C131583.

An ependymal tumor affecting the cerebellum and a brain ventricle. 